\title{
Las lenguas como patrimonio. El principio de prioridad
}

\section{Julio Calvo Pérez}

Está lejos de acertar el DRAE $\left(21^{\mathrm{a}}\right.$ ed. $)$ cuando define la palabra patrimonio con semas excluyentes de economía. La primera acepción, por ejemplo, dice que patrimonio es la "hacienda que una persona ha heredado de sus ascendientes". En términos jurídicos define igualmente que es el "conjunto de bienes pertenecientes a una persona natural o jurídica, o afectos a un fin, susceptibles de estimación económica". Desde la perspectiva global, el diccionario es no menos impreciso: "Suma de los valores asignados, para un momento de tiempo, a los recursos disponibles de un país, que se utilizan para la vida económica". De estos conceptos generales de herencia individual y colectiva, se suele pasar a las aportaciones monumentales (Choay 1992), que por ser más indelebles, han quedado para recuerdo de glorias pasadas bien sepultadas y luego arqueológicamente recuperadas (Nazca / Segóbriga), bien enhiestas aunque durante tiempo encubiertas (Machu Picchu / Mérida), bien evidentes y manifiestas (Cuzco / Santiago como ciudades monumentales), etc. Con este criterio para asignar y distribuir riqueza, para conocer y reconocer la excelsitud del pasado, no me extraña que, salvo honrosas excepciones, en nuestros países (España y Perú) se hayan olvidado, por ejemplo, las aportaciones misioneras al estudio y normalización de las lenguas amerindias, o sea las aportaciones espirituales, pero se tenga constantemente en el candelero el oro de Cajamarca o la plata de los galeones. Pero lo cierto es que España se empobreció hasta límites insostenibles hasta la fecha en que se independizaron las colonias, pero ha ennoblecido su lengua con constantes aportes léxicos y gramaticales indígenas hasta el momento presente. Otra cosa es que el mismo DRAE, ajeno a una realidad tan ampliamente compartida, reduzca tal aporte a unas pocas decenas de palabras y lo haga, además, con tanta desgana e improvisación (cf. para el quechua y el aimara, Calvo 1995a). Decía Calderón, uno de los dramaturgos más importantes del Barroco, ampliamente difundido, y representado e imitado, en Perú (Lohmann 1945) que:
Al Rey la hacienda y la vida se ha de dar; pero el honor es patrimonio del alma, y el alma sólo es de Dios (El Alcalde de Zalamea, 873-876)

Hemos de parafrasear al escritor madrileño sustituyendo la palabra honor por la palabra lengua, para advertir, al inicio de este trabajo, que la definición económica de patrimonio corresponde al individuo material o al estado capitalista, imperialista o socialista, pero que la definición cultural, en la que entran honor y lengua, corresponde a lo 
más profundo de nuestra espiritualidad. ¡Lástima que los versos más célebres de Calderón no hayan propiciado una acepción en este sentido, abstracto pero realista, a los señores de la Academia! Y si esto es pedir mucho, sería más exigente todavía que el DRAE incorporara las últimas acepciones sobre patrimonio y cultura, aquellas que tienen que ver, más que con el Dios dador de la entidad inmutable, con los pueblos mismos que la forjan en un proceso en que la cultura es "no sólo la suma de bienes y experiencias propios y heredados, sino el grado de conciencia de sí que tiene determinado grupo humano" (Bákula 2000). La toma de conciencia del pueblo radica antes que nada, como se sabe desde el Renacimiento, en la leche que se mama y en la lengua que se habla en el seno familiar: esta concienciación llega incluso a lo sagrado con el Romanticismo y la individualización a ultranza del hombre del siglo XX.

El primer paso en todo aquello que comprende el ámbito patrimonial es el reconocimiento de la herencia recibida. Luego hay otros: su conservación y ampliación y finalmente su transmisión a los descendientes. Del mismo modo que el hombre comete error incalculable destruyendo el entorno y desertizando el hábitat de sus hijos, igualmente atenta contra los principios básicos de sus derechos cuando conculca los derechos de una lengua, cuando la tergiversa y malinterpreta, cuando la olvida y minimiza y, finalmente, cuando la obstaculiza y la niega. Todo esto ha sucedido con el quechua y el aimara en Perú, como si la lengua fuera ajena a los bienes nacionales. Es tan sagrada una piedra de Machu Picchu como una palabra de estas lenguas: tan importante es el Intiwatana, anteayer descubierto y hoy lacerado, como el significado de sus dos lexemas juntos Inti "sol", watay "atar, calcular su recorrido". Lamentablemente, contra ambos se pueden cometer actos de lesa irresponsabilidad. El resultado de uno de ellos es aquel en que el indígena niega su propia lengua u odia conocerla, de donde nace la gran paradoja, la imposibilidad de los discursos indigenistas, los cuales se hacen casi siempre al margen del indio, aunque se pretenda hacerlos por él.

La importancia de las lenguas como patrimonio de los pueblos no puede caer en saco roto, pese a que sean pocos los autores que las incluyen en las listas de los bienes preservables o recuperables o se les consideren inoperantes, patrimonialmente hablando, por muy distintivos que sean desde la perspectiva antropológica (Prats 1997: 37).
Enseñamos a nuestros visitantes lo mejor y más antiguo que tenemos: la catedral del Cuzco, las ruinas de Sacsayhuamán, el centro histórico de Lima o el Valle del Colca. Nuestro orgullo es nuestro patrimonio en el que como se observa últimamente se incluye la flora y la fauna, y hasta el paisaje. Pero el patrimonio de un pueblo va más allá: su historia, su pensamiento, las costumbres de sus habitantes, el folklore, los nombres que estos dan a las cosas y la diferente distribución de los campos léxicos, ha de importar con preferencia y hemos de mentalizarnos en que existe una vertiente espiritual (o inmaterial) que no podemos contemplar sin ellos. En épocas de fuerte globalización como la nuestra, los aportes propios ancestrales (y aquí incluyo a los mestizos) son de un valor extraordinario, aunque, en general, no suelan reconocerse. Pongamos un ejemplo: Raúl Porras Barrenechea, un importante historiador cuyas aportaciones al patrimonio histórico han sido decisivas, desconocía el quechua. Conocer el quechua no es un asunto que deba alarmarnos en principio: el quechua lo conocen sus hablantes, especialmente los relativamente pocos monolingües que quedan y sus aportaciones, absolutamente orales, se pierden por entre el viento helado de la puna o el vapor soporífero de las yungas. Su voz no llega a materializarse casi nunca en palabras indelebles, grabadas en la piedra o reproducidas de modo múltiple por el ciclostilado. Parecen importar poco. Aquí radica uno de los errores del ejemplo que estoy comentando: las palabras las repite el niño con su padre y su madre hasta que por mera repetición las aprende, asimila y usa con precisión. Son palabras con pretensiones imperecederas, que en ocasiones rebasan los siglos o vencen a las ruinas más augustas. Palabras como supay "espíritu (de los muertos); duende; aparición", hucha "4alta (pública); delito", como challwa "pescado" o marqay "abrazar" eran anteriores a la llegada de los españoles y siguen perennes hoy entre los hablantes, aunque a veces con acepciones nuevas (supay "diablo", hucha "pecado"). Cuando se les pone en el contexto adecuado, los quechuahablantes y los aimarahablantes nos descubren cadenas significantes que vienen de mucho más atrás que las ruinas más monumentales: p'unchaw "día", urpi "paloma", much'ay "adorar". Incluso hay palabras que ya existían interprestadas entre los dos pueblos citados seguramente desde antes de Tiahuanaco: pura "ambos", coca "coca", totora "junco del lago Titicaca". La voz es sutil y delicada, se pierde a los pocos instantes de ser dicha, pero tiene la gran virtud de reproducirse tiempo después, como esas palabras que uno no ha oido desde 
niño y por alguna la razón le revientan en la boca o le sorprenden el oído. Recuerdo como, en 1986, hice volver a evocar su lengua a Elsa Salas, una anciana de Oruro que había vivido ya cuarenta años en España. Nunca pudo dejar de agradecerme que le hiciera resucitar su lengua y comprender que 'la quichua' que ella hablaba no era un mero dialecto sin valor, que estaba escrita en los libros y que valía la pena revivir para morir con ella. Yo tampoco pude dejar de estar atónito ante cada palabra nueva del altiplano, antes de pisar estas tierras rotundas: conocía llama y mitma, pero ignoraba pichana "escoba" y por supuesto, no sabía que pichay "barrer" pudiera tener las acepciones que he recogido hasta el momento en mi diccionario (Calvo en prep.) y que, una vez exoneradas de ejemplos, son las siguientes, junto con sus derivados:

PICHAY (v.), barrer, limpiar \{con escoba; abalear; raer; rozar; desatascar; [gen.], limpiar; despejar, quitar \{trastos\}; expurgar; desbrozar \{con raíz\}; borrar, sacar \{lustre\}; anular, obliterar; «fig.", sonarse $\{$ la nariz\}; purgarse; (sust.), aseo, higiene, limpieza; purga.

PICHA PICHA, laxante, purgante / PICHACHINA (q'upa), basura / PICHAKUNA (qhuña pichakuna), moquero, pañuelo \{para la nariz $/ \mathrm{PICHA}$ NA, escoba, escobón, pichana; escobilla, plumero; baleo; balea; «fam.», borrador; barredura/

PICHANA HANPI, laxante, revulsivo / PICHASQA, barredura / PICHANAYAY, difuminar / PICHAPAKUQ, barrendero / PICHACHIKUY «fig.», conjurar, exorcizar; (sust.), exorcismo / PICHARIKUY "fam." (chiraray), despejarse, limpiarse $\{$ el cielo\}/ PICHARQAKAMUY (picharqukuy), abrir \{el día\}, disiparse $\{$ las nubes $\}$.

Es una palabra anodina, se me dirá. Sí, pero en las palabras corrientes o efímeras es donde se dan los usos generales de los pueblos, las manifestaciones que también hay que conservar patrimonialmente, lejos de la ingenuidad de que el quechua es dulce o el aimara sonoro y otras paparruchas por el estilo. La prueba está en que si no se las conoce a fondo son difíciles de apreciar y guardar: la Iglesia adoptó la forma pichachikuy para referirse al exorcismo, por ejemplo, y eso fue gracias al conocimiento exacto de las prácticas andinas y el concepto subyacente ${ }^{1}$. Abogo por la búsqueda, el reconocimiento, la ordenación y conservación de ese patrimonio, todavía vivo. Incluyo la necesidad de que se tengan en cuenta tales extremos en la enseñanza y en el inculcamiento general de su sensibilidad. Se me dirá: ¿Y dónde están las palabras grandes? Ahí entra en juego el ejemplo, voluntariamente interrumpido, sobre Porras. Este autor dejó un legado histórico importante, que incluía el orden lingüístico (tomo I: Legado quechua, de sus Obras completas), pero partía de importantes limitaciones. Por eso no pudo ser capaz de distinguir las palabras corrientes como pichay (ni que se llame "barrer" al hecho de quedar raso el cielo, despejado de nubes) de las palabras grandes a las que ya me refiero. Él decía que el hombre andino era equilibrado, juicioso, que tenía un sentido grande de la justicia, por tener la palabra chawpi "centro", al tiempo que criticaba que "no hay una palabra precisa para ley" en lengua andina (p. 248). Dice Álvarez Brun, su prologuista:

"Hay que ver cómo Porras interpreta, por ejemplo, la partícula quechua chaupique implica, según él, "una conciliación de contrarios o el justo medio".

La palabra chaupi significa el término medio de las cosas [corrobora], de los lugares, del tiempo y hasta de la conducta humana por lo que Porras lo califica como el arquetipo quechua o sea el areté incaico de la ecuanimidad y la mesura. Otros vocablos [reconoce] vendrían a representar lo mismo y significar lo contrario como el relativo al abuso en el mando. En todo caso Porras encuentra palabras y frases que dan a conocer normas morales 0 de conducta muy significa recisa]. Porras no podía penetrar más allá de lo que se consigna en los vocabularios porque desconocía el quechua [rectifica], que sólo por su talento y cultura podía superar para ofrecernos los conceptos valorativos de la lengua de los Incas" (p. LXX-LXXI).

Un análisis somero del ejemplo nos pone en guardia: lo mismo que un acercamiento esporádico a un cuadro religioso de la escuela cuzqueña de los siglos XVI y XVII o una visita apresurada a las ruinas de Pachacámac. ¿Quién no ha oído decir a algún guía que Machu Picchu fue construido por extraterrestres? No creo que haya ninguna lengua que carezca de una palabra para centro de algo, ni

I Pichay, para el diccionario de Perruod-Chouvenc, que recoge la tradición lexicográlica quechua, es "curar entermos supersticiosumente sobándolos en cobaya. aji y otras cosas". En Gonzílez Holguin kemos: "animayta, o vcusonquyta pichani. Limpiar el ánima y conciencia". lugar donde se aprecia la imbricación religiosa cilada. 
creo tampoco que el sentido de la ecuanimidad y la sindéresis sea compartido por igual por cada hablante que usa el término correspondiente. Eso para empezar. Además, ¿cómo se descubre que esa es una palabra grande? De ningún modo, porque no lo es: es una palabra corriente. Veamos algunas acepciones de Calvo (en prep.) -dejo de lado la mayoría de los derivados, que son del mismo corte semántico y los ejemplos contextualizadores-:

Obsérvese que no hay nada sublime en estos conceptos: unos aluden al espacio y otros al tiempo y nada más. Sólo cuatro derivados (de los veinticinco recogidos por mí) parecen acercarnos, no sé si erróneamente, a conceptos más sublimes:

CHAWPINPI KAY, interceder, mediar / CHAWPIPI KAY «fig.", temple, término medio / CHAWPINAY, arbitrar, interponerse; mediar; [c.-p.], centrar (la pieza); (sust.), inciso / CHAWPIYAY, mediar \{en un lugar\}.

Son metáforas que refieren a que el hablante puede colocarse en medio, es decir, interceder ante otros que discuten o pelean. No sé si no será, incluso, un calco semántico del español, donde medio / mediar metaforizan del mismo modo la realidad. Véase que chawpinay significa también y preferentemente "centrar la pieza de caza" para matarla de certero disparo. En cualquier caso, este tipo de metaforizaciones son universales (Lakoff \& Johnson 1995). No es cierto, por otro lado, que no existan palabras para "ley" en quechua: kama-es la raíz de toda ley y creación ordenada. Esta sí que es palabra monumental, como se comprueba en el resumen siguiente (también de Calvo en prep.):

KAMAY [abstr.] (kachiy), animar, crear, formar, hacer, modelar, plasmar; producir \{de la nada\}; (kamachiy), mandar, obligar, ordenar; promulgar // KAMACHIY [abstr.], legislar, mandar, ordenar; imponer; condicionar, supeditar; (kamachikuy), atender, considerar ... lisiyunta allinta kamachiy, atiende bien la lección; organizar; tener \{poder o capacidad\}; custodiar; aforar; administrar, gobernar, regir; usar, utilizar; forzar, precisar \{a la acción [+cant.]\} // KAMACHIKUY, autorizar, dar \{poderes\}; camachicar, ordenar; apoderar; predominar; suponer; atender; (fr.) "fam.", atar y desatar, contar²; (sust.) [abstr.], régimen, sistema \{político\}; subordinación; normativa, régimen; canon, precepto, regla; fuero, jurisdicción; plebiscito, ordenanza; plebiscito \{con consulta al pueblo\}; resolución \{del pueblo\}; constitución; mo- ción \{de censura\}; necesidad \{de auxilio\}, precisión; razonamiento; autorización, poder; carta blanca; dignidad \{del gobernante\}, imperio; predominio; inspiración \{externa\}, moción; legalidad.

Se trata de un resumen sucinto de sus múltiples relaciones, en que a las designaciones antiguas se añaden aquellas otras más modernas pero derivadas directamente de ellas, lo que implica que el concepto sigue vivo. Hay, además, una imprecisión en Porras: en el mismo González Holguín (1608), al que prologa, se lee que ley es camachicusccan simi "palabra de orden" (y no sólo apup simin "palabra del señor"). El concepto de kamay "hacer", con su causativo kamachiy y el causativo-reflexivo kamachikuy ("resultado de hacerse mandar") nos lleva a todos los entresijos de la "gobernación" bien es verdad que a través de la boca (simin) - es decir, de la costumbre-, al no existir ley escrita quechua reconocible ni siquiera en los quipos. Y, en efecto, todo esto tiene que ver con ley concreta (la ley abstracta es kamachiy) que se refleja en la siguiente entrada:

KAMACHI [act.], decreto, designación, edicto, ley \{humana\}; acto, disposición \{legal\}; ( $k a$ chay), mandato, norma, orden \{particular\}, precepto; consigna; regla; mandamiento; estatuto; ( $\mathrm{ka}$ machi qilqa), código; "fig." (yachay), línea, orientación, tendencia.

En esta misma línea, permítaseme aludir al concepto que encierra toda la fuerza del equilibrio, del justo medio y del sentido común que anhelaba Porras Barrenechea. No es chawpi, sino chanin, su significante quechua. Esta es una de las grandes palabras del idioma, lo que se aprecia a simple vista, a través de las múltiples acepciones de la palabra-vedette y de los diversísimos derivados léxicos que elido en su totalidad, junto con el verbo matriz chaniy "arbitrar":

CHANIN (sust.) [ \pm mat.], estipendio, pitanza; [-mat.], ajuste, alzado \{del precio\}; "fig.", precio; $\{$ psiq.] [reg.]\}, criterio; esfuerzo \{por conseguir algo\}; "fig." (chaninchay), aplomo, circunspección, serenidad; [abstr.], precisión, rigor; exactitud, verdad; equilibrio, proporción; contemporización; (chanin kay), prudencia; austeridad; autoridad, crédito; fama, reputación; estima, valía;

\footnotetext{
2 Prescindo en esce y en los demás ejemplos de glasar las abreviaturas (más bien obvias) de las equivalencias. La intención no es explicar el diccionario, sino aproximar inductivamente al lector a ha ideal que preside el ejemplo.
} 
razón; «fig., fam.» (miqu), importancia, tomo; [ \pm mat.], casta, calidad; (adj.) $\{[-$ mat.] [+cant.]\}, válido; [=], cabal, exacto; justo, neto; alícuota, proporcional; justo, verídico; cierto; genuino, legítimo; correcto; lógico; [ \pm cant.], apropiado; [+cant.], excelente; «fam.», potosí; [cant.], oficial; real; [abstr.] «fig.», alto, solemne; "cult.», canónico; [psíq.] fiel, leal; formal, serio; riguroso, severo; cuerdo; [hum.] «fig.», acreedor \{de algo\}.

La palabra chanin, aún albergando conceptos que tienen que ver con lo mercantilista, se decanta en seguida por la línea virtual, ya abstracta, de las relaciones humanas y el alcance espiritual y social que le dan los quechuahablantes: al lado de justicia y proporción, tenemos una idea restrictiva de rigor y esfuerzo, más otra aperturista de contemporización y transigencia. Prevalece, no obstante, la primera idea, ya que chanin, en calidad de adjetivo, carga las tintas sobre "riguroso, severo", aunque el predominio absoluto sea de equilibrio: "apropiado, justo, legítimo, proporcional", son las equivalencias predominantes. Sobre las bases de una estructuración léxica de este tipo, se va entonces a los derivados para ver en qué grado se aproximan o se alejan de esta idea principal. No es el momento de hacer aquí un análisis pormenorizado del concepto, concepto que, por otra parte, existe en todas las culturas; solamente diré que a la vista de los derivados las previsiones se cumplen. Chaninchay, por ejemplo, la palabra más importante y común del conjunto derivado se glosa así (reduzco la entrada a equivalencias desnudas):

CHANINCHAY $\{[$ hum.] $\neg[ \pm$ mat.]\} [gen.], cuantificar, precisar; $\{[\mathrm{com}].[>]\}$, apreciar, aumen$\operatorname{tar}\{$ el valor\}, preciar; [=], cuadrar \{las cuentas\}; justipreciar, tasar; aplicar, ponderar; sopesar; aquilatar, cifrar; valorar, valorizar, valuar; "fig.", vender \{en su precio\}; \{[hum.] $\neg[-$ mat.]\}, ajustar, capitular, concertar, pactar; calcular, estimar; evaluar; concertar $\{$ el precio\}; [neg.], cancelar; $\{$ hum.] $\neg[ \pm$ mat.] $\neg$ [hum.]\}, remunerar; [abstr.], censurar; calificar, juzgar \{los conocimientos\}; [ \pm cant.], argumentar, discutir, impugnar; revalidar; [+cant.], abonar, dar \{por cierto\}; [=], acreditar, dar \{fe\}; (kuskachay), equilibrar; [ $>$ (hatunchay), enaltecer \{en parte\}; [ >>] (qhapaqchay), acreditar, ennoblecer \{bastante\}; [t.], finiquitar, sanear; [mat.] "fig." (yapay), aumentar, pronunciarse; (sust.) [col.], convención, coto \{de mercaderes\}; \{[ \pm mat.] [indiv.]\}, ganancia; [-mat.], aquilatamiento, balance; presupuesto; [psíq.], fide- lidad, lealtad; (chanin), aplomo; [=] (sumaqchay), curia, cuidado, esmero; cordura; [abstr.] (chanin kay), imparcialidad, juicio; criterio; acuerdo, reflexión; «fig.», jugo, zumo; « \pm nec.», apariencia, probabilidad.

La más excepcional palabra del quechua, aquella en que se concentra la ontología quechua es kay "ser" (Calvo, 1995b), que también se traduce por "estar; haber, tener, poseer; existir, suceder, acontecer"... Como kay es "esto", parece que su tensión sea hacia la existencia, más que a la esencia del ser. En cualquier caso, refleja el viaje a la sustancia, con predominio sobre la forma, ya que kay subyace a cualquier formación abstracta en quechua: sumaq kay es "hermosura" (sumaq "bello"), runa kayes "humanidad" (runa "ser humano"), etc. Y esta palabra pervive y pervivirá libre o como sufijo dependiente, siendo tan antigua como la propia lengua, anterior a la formación del imperio inca y posterior a su destrucción; diaria en su expresión diversa y profusa en sus equivalencias sobre lenguas de conceptos filosóficos más atomísticos de la cultura occidental. Como dije en su momento esta palabra y el concepto que encierra "ineludiblemente constituye uno de los rasgos más enérgicos de confluencia, de globalidad de significado, de conjunción filosófica y psicológica" (ibíd. p. 20). Otra palabra de entidad primaria en quechua es pacha, que encierra el tetragrama de las cuatro dimensiones del hombre al significar "espacio; tiempo", siendo así concomitante con la idea existencialista apuntada antes. Sobre ella, infinidad de conceptualizaciones desarrolladas con rigor y plenitud deberían dar la pauta para conocer a un pueblo que no merece la servidumbre vital por la que pasa. Las palabras para prestar y devolver lo prestado en sí mismo o en materia equivalente (mañay/manuy), las palabras para comprar y vender (siempre sobre la base del intercambio o ranti- ) podrían decirnos mucho también de la manera de vivir de un pueblo.

He hecho una primera discriminación entre palabras comunes y palabras símbolo de un pueblo. He asumido que para un análisis pormenorizado lo primero que hace falta es el recojo exhaustivo de datos y después una revisión a fondo de los conceptos que encierran. Sin duda que este presente de la lengua es el que se echa de menos en los estudios de Porras, porque el léxico de las lenguas es de una riqueza tan sorprendente y de una variedad tan ilimi- 
tada que nos obliga a que lo recopilemos y estudiemos, o al menos a que no lo trivialicemos ni perdamos. Afecta directamente a nuestro patrimonio como herencia y a nuestro futuro como legado. Del mismo modo que recogemos y estudiamos la flora y la fauna, la gastronomía y la música, debemos recoger y estudiar muchas más cosas todavía. Pero la lengua es prioritaria y está por encima de todas ellas: los sistemas de conceptualización de un pueblo sólo se pueden respetar si se conocen y para conocerlos hay que entrar a fondo en los entresijos de la lengua que hablan.

El patrimonio es también herencia cultural, palabras e ideas del ancestro, conceptos diseminados por entre las crónicas, logros estéticos que se encierran en las obras literarias del pasado. Ollantay, por ejemplo, había sido traducida a muchas lenguas (ruso, checo, latín, inglés, francés y, por supuesto, español), pero el maltrato a que se había visto abocada la había convertido en una especie de cajón de sastre en que se mezclaban todas las versiones. Haberle lavado la cara, como hizo el CERA "Bartolomé de las Casas", con su encargo a un lingüista, ha supuesto la recuperación de su textura original. $Y$ se ha hecho con el mismo criterio que el restaurador que recupera un cuadro, el paleógrafo que precisa una inscripción o el arqueólogo que ordena las muestras de una excavación. Pero sucede que un pueblo que no tiene sino prejuicios sobre su pasado cultural, carece de capacidad crítica para valorar la recuperación del patrimonio. Por ello se siguen haciendo antologías con versiones antiguas poco rigurosas y se siguen propiciando análisis ideológicos, carentes de la más mínima sistematización y solvencia. Lo mismo que Ollantay, otras obras como Usca Paucar o El pobre más rico, habrán de ponerse igualmente al alcance de los jóvenes y hasta exportarse a países próximos patrimonialmente hablando. Perú es un país en auge y así se espera que sea también el interés por su cultura y por su patrimonio lingüístico (que compromete más de cincuenta lenguas). Una cultura que algunos indigenoides o puristas detienen enigmáticamente en el Qosqo glorioso y patochadas por el estilo no es una cultura auténtica, sino impostada, la cual es necesario superar con rapidez preparando especialistas desde las instituciones educativas que incentivan el patrimonio y el turismo. Ni uno ni otro pervive por sus exotismos, sino por sus autenticidades, por más que la ley turís- tica de la oferta y la demanda parezcan imponer su ley. Y la lengua tiene mucho que decir, sobre todo la quechua que es la que se focaliza aquí y la que ha dejado huellas transcendentes. También, aunque en menor grado, la aimara. Así como chakra "chacra, parcela de cultivo" se desenvolvió desde esta lengua a todas las del entorno, fue la cultura quechumara en su totalidad la que marcó durante siglos las directrices operativas de otros pueblos, no siempre sojuzgados. Es preciso, en esa línea, reconocer que el mestizaje ha tenido mucho que ver en la formación literaria, ideológica, mítica de nuestros ancestros peruanos: al lado de la hermosa adaptación del quechua más genuino a la explicación de la doctrina del Catecismo de la Doctrina Cristiana (1584), se hallan también las obras recogidas con manipulación latente pero prevista: el Manuscrito de Huarochirí. Pero ello no quita para que su estudio nos sea provechoso y sirva para entender las claves de su tiempo. Sucede así, que la lengua que trasmite todas estas manifestaciones haya de ser estudiada también con criterios históricos, sin necesidad de transplantarla a la que como presente me refería arriba. Las obra monumentales de Domingo de Santo Tomás y de González Holguín para el quechua, de Bertonio para el aimara, necesitan ser puestas al alcance de todos, como se pone un museo o la fachada restaurada de un palacio. Pero todo esto, que se hace todavía hoy de manera tópica, ha de sufrir un cambio profundo, emanado de las nuevas directrices de los estudios de patrimonio: se requiere que los nuevos especialistas tengan conocimientos directos de aspectos fundamentales de la lengua que hace de soporte general y que los estudios de lengua se inserten de manera troncal en los estudios turísticos y patrimoniales. Desde ahora, lo que se pide es un buen conocimiento de la lengua presente que nos ayude a interpretar mejor la lengua del pasado, en este orden. Después se podrá enseñar el pasado patrimonialmente más valioso, interpretado en claves actuales. Esto debe extenderse al resto de lenguas peruanas, el español incluido, porque toda lengua es, en cualquier circunstancia, sujeto de patrimonio. Habrá que ver también qué se prevé para el futuro. Patrimonio lingüístico es búsqueda permanente de lo que se tiene hoy, que es evanescente o efímero, y que se fije para su posterior tenencia y disfrute. ¿De qué nos sirve que recuperemos concienzudamente el pasado lingüístico, de qué sirve incluso que verifiquemos un presente en toda su 
diversidad y erudita interpretación, si no somos capaces de proyectarlo hacia el futuro? Las lenguas indígenas de hoy se deterioran en beneficio del inglés y el español, algunas desaparecen y mueren sin que hayan sido recogidas sus lindezas literarias, sin que hayan sido aprendidas en las escuelas correspondientes ni mostradas por los estudiosos en su justa instrumentalidad. Hay a veces una obsesión por aspectos históricos de difícil acceso o imposible acometida (como el de indagar si queda algún hablante perdido de la lengua mochica), mientras se produce la más inexplicable dejación por lo vivo. ¿Por qué no se estudia el mundo complejo de los campas, de los arahua, de los shipibo o los bora?. La recogida léxica en profundidad, apoyada en lo etnológico y antropológico (como acaba de hacer Gerzenstein con el maká: Gerzenstein, 1999), la gramaticalización pragmática de las lenguas de esos pueblos, es una exigencia de conservación del patrimonio con vistas al futuro que es improrrogable y que necesita urgentemente un empuje nacional. Se comprenderá, en este punto, que patrimonio como visión economicista y patrimonio como visión espiritual, cultural y social, se necesitan mutuamente. Hace falta dinero y economía creciente para conocer y ordenar bien el patrimonio de los pueblos, porque es un asunto de poder (Prats 1997), pero hace falta saber también que conforme los desequilibrios económicos crecen y el neoliberalismo prende por la globalidad del planeta, la sensibilidad por lo más genuino del patrimonio disminuye y se extiende por doquier el peligro de una uniformización desoladora. Al tiempo, una fragmentación de la experiencia propiciada por el turismo, es el camino para apropiarse de aspectos en los que no cabe el análisis, sino la mínima referencia, el nombre a veces inventado. Es lo que con palabra inteligente ha llamado Urbano (2000: 24) "volatilidad" del patrimonio. El patrimonio de los pueblos no es uniforme, porque entonces no es patrimonio, pero tampoco debe comprenderse como una experiencia fragmentaria, sino devenida con el tiempo y llamada a ser perdurable: ni el aji de gallina ni el vino de Ica constituyen toda la riqueza culinaria, ni el viaje por el Camino Inca es lo único que debe ofrecerse al estudioso y al viajero. Sin embargo, las recetas son cambiantes y los paisajes mutables.

Por las razones anteriores, el patrimonio ha de extenderse a todas las manifestaciones del pensamiento y la cultura y especialmente a las lenguas que encaminan todas las posibilidades interpretativas de una herencia cultural y nos abocan igualmente a una conservación futura. No hay nada más desolador que el guía que dice siempre lo mismo ante la misma imagen o el mismo cuadro, lo que puede extenderse a que no hay nada más uniformador y restrictivo que todos los guías turísticos comentan lo mismo siempre ante las mismas obras de arte y así sucesivamente porque la única variable que al parecer cuenta es la del turista, siempre fugaz y con la vista puesta en el entorno o la superficialidad del fenómeno. Aún siendo así en parte - el turismo es, fundamentalmente, un "valor añadido"-, la creatividad pasa por una interpretación lingüística profunda, ya que, si no, deriva en mera improvisación y superficialidad que igualmente desfavorecen, junto con la monotonía, lo cambiante de la cultura y la diversidad de posibilidades de interpretación de nuestro bagaje cultural, natural y artístico.

Se dice que la crisis de identidad (Tenier 2000) de la sociedad moderna lleva a dos extremos: a la búsqueda de identidad a cualquier precio para equilibrar la balanza, o a la investigación de la más mínima diferenciación en cualquier marco para acotar un terreno patrimonial que traiga alivio cohesionador. La búsqueda de identidad tiene que ver especialmente con el patrimonio diferencial, soporte de la identidad, no con el monumento emblemático, soporte de la memoria, que es sólo una parte. La lengua se ubica, sin duda, en esas coordenadas, ya que es fuente de múltiple diferenciación, pero también vía resolutiva para la búsqueda profunda de la identidad, debido a su capacidad de representación simbólica. Además la lengua es patrimonio prototípicamente hablando, porque se hereda de padres a hijos, por la vía más tradicional de la madre (de ahí lo de "lengua materna") y porque es el camino más inmediato para la adquisición de la cultura: costumbres, modos de vida, etc. Con la adquisición de la lengua se construye directamente nuestro mundo (Piaget 1976 [1950]), pero $\sin$ el auxilio familiar y social no es posible adquirirla (Vygotsky 1972). Ello nos lleva a precisar en qué sentido se ha de entender la lengua como patrimonio. De cierta manera, las lenguas constan de palabras en que el nombrar es juramento o conjuro (Azurmendi 2000), constan de palabras impronunciables para los demás y difícilmente asumibles en el conjunto de sus connotaciones. Son palabras exclusivas que aluden al há- 
bitat y al significado íntimo del hábitat, a sus creaciones y a los símbolos inalienables que encarnan. Por eso algunos ven tan mal la intromisión del ajeno en sus propiedades -patrimonio y propiedad exclusiva de las lenguas-cuando alguien de fuera se apropia de ellas e intenta utilizarlas con mejor o peor fortuna. De hecho, las lenguas no se prestan a una adquisición total si no es en el seno de la sociedad y desde la más tierna infancia de sus usuarios. En este sentido, lengua es uso y uso propio, "matrimonio" (patrimonio de puertas adentro). La diglosia (Ferguson 1965) no muestra sino esa diferenciación, con múltiples variables en que la lengua general se usa para todas las cosas públicas, pero la particular se restringe a la familia y a los círculos más íntimos: es su vertiente connotativa o expresiva.

Aquí el binomio turismo-patrimonio no cuadra. El turista resbala sobre las manifestaciones patrimoniales del otro y, por eso, no las asume o interioriza, ni tampoco se le permite una intromisión que vaya más allá del zaguán del contacto esporádico, la palabra suelta o el intercambio de códigos de paso. Así resulta que una lengua internacional como el inglés o el español, o como lo fueron en tiempos el quechua y otras lenguas generales amerindias, no es patrimonio de nadie en particular, sino vehículo administrativo al servicio de todos: necesita ser conocida por necesidad, pero no se la patrimonializa en afectividad personal. Por todo lo anterior, no conviene que confundamos que lengua como patrimonio no equivale a exhibición ante los demás como se les muestran unas ruinas o un museo (caso de la representación en quechua del Inti Raymi): la lengua ha de concebirse como instrumento interno para mejorar la calidad explicativa del mundo patrimonial, debiendo conocerse mejor y más diversamente en beneficio de la ciudadanía que se deleita ante la obra expuesta o la consume superficialmente. La única proyección patrimonial que la lengua puede hacer entonces, de cara al consumo, no es la del cómo se formalizan en profundidad sus conceptos más íntimos, es decir cómo opera en el constructo social, sino la de su manifestación externa como nominalizadora de los objetos más públicos: un tumi no es sin más un cuchillo, una pukara no es simplemente una fortaleza, un tambo no es sino de lejos una posada y así sucesivamente. De hecho, pues, interesa más al turista el diccionario que la gramática, y de éste más la expresión referencial que la ex- presiva o apelativa. En cambio, para el profesional de turismo, esto debe ser sólo un índice superficial de su conocimiento más profundo: saber cuatro palabras es simple y llanamente diletantismo inútil, obviamente diferenciador, pero sin función operativa.

Otro aspecto en que la lengua cuadra prototípicamente a la hora de valorarse como patrimonio es que no es algo muerto, salvo que se trate una lengua extinta como ocurre con la de la cultura grecolatina (el griego existe modernizado y el latín desapareció difuminado entre las lenguas romances). La lengua se revela entonces como elemento de la memoria sin ser necesariamente algo estático, como recuerdo o conservación de algo que fue y sigue siendo. El museo se concebía antes como algo inmutable, con recuerdos del pasado encerrados en vitrinas, ajenos al flujo emotivo del espectador, y hoy se ha convertido en espacio dinámico, proclive a ser manipulado; la lengua, en cambio, es vívida, asoma por doquier, existía y existe en proceso, pero no se presta a su captación externa fácil, de ahí la "invención manipulativa" que ejemplifiqué más arri$\mathrm{ba}^{3}$. Además la lengua seguirá existiendo, lo que correlaciona con la idea de patrimonio como proceso, como evolución, como dinamismo orientado hacia un futuro que no cesa.

Las lenguas, se me dirá, son perecederas. Eso es cierto, pero abarcan con su capacidad potencial al resto del patrimonio, después de todo también perecedero ( $\mathrm{y}$ en el que merece tanta atención el cambio como la continuidad), de los pueblos que las hablan: podrá haber muerto una lengua como el latín y quedar un acueducto como el de Segovia, pero éste no podrá ser debidamente descrito sin las palabras-soporte que encaminaron su nombre como ingenio (aquae + ductus). He aquí su principal salvaguarda. Es decir, que el lenguaje no es sólo memoria, sino recuperación, repetición in extremis del acto creativo que supuso el acrecentamiento de la patrimonialidad en cierta época. Es tanto un re-

\footnotetext{
3 El concepto aparece en Hobsbawm \& Ranger (1998), para quienes inventar, en este contexto, no es tanto crear mundos falsos intencionadamente y para aprovechamiento personal. sino buxar aplicaciones que no se justifican y que, a la larga, sólo se hallan en la mente de su creador. La invención patrimonial $x$ aplica al individuo (caso de Porras Barrenechea) tanto como la reconsinucción patrimonial al poder que la sustenta (Prats 1997).
} 
torno al pasado que fue como un salto al futuro que será, apoyado en la seguridad de que los instrumentos lingüísticos pueden ser actualizados para que se cierre el bucle temporal. Como dice Tenier (2000) se habrá cambiado "el objeto [patrimonial] en recurso". Humboldt (1836) supo verlo hace casi dos siglos cuando advirtió que la lengua no es meramente ergon (producto enlatado), sino energeia (uso dinámico que nos recorre en todas las actividades de nuestra vida). Como tal energeia, la lengua debe ser asumida por las instancias que preparan a los profesionales del patrimonio para que sea un instrumento más, en forma de recurso omnímodo, para entender mejor el resto de los objetos que comprenden el acervo patrimonial bajo su responsabilidad inmediata. Si la gestión patrimonial es un recurso continuado "que sirve para una experiencia presente y seguramente para una necesidad futura" (Tenier ibíd. p. 181), no cabe duda de que la lengua como patrimonio es el principal medio para que el recurso patrimonial en su totalidad sea administrado eficazmente.

Según lo comentado hasta aquí, el patrimonio espiritual de un pueblo domina supraestructuralmente sobre el material más tangible y es además el resguardo contra la volatilidad que preside los gustos particulares de los turistas 0 la tendencia trivializadora de los detentadores del discurso en su vertiente más política: Decir que Valencia es la paella y Portugal el bacalao, que el quechua es la lengua imperial del Cuzco es un fiasco, lo mismo que decir que EE.UU. es la tierra de la libertad o las Vegas la capital del juego. Sobre el patrimonio espiritual hay todavía un instrumento más poderoso que controla a los otros: la lengua o lenguas de un pueblo. He aquí formulado entonces lo que se podría llamar el principio de prioridad patrimonial según el cual cuantos más procesos lingüísticos se requieran para atender a un hecho patrimonial, más seguros estaremos de su salvaguarda y de su prolongación en el tiempo. El hecho mitológico, formulado siempre en palabras, es prototípico de esta prioridad. Habrá que entender, sin embargo, que aunque por esta vía haya que considerar a la sociedad misma como objeto total de patrimonio, la prioridad lingüística no es preferencia absoluta (como si el estudiante de patrimonio fuera meramente un filólogo), sino antelación (prelación en el tiempo de los estudios lingüísticos pertinentes).
El final de este ensayo pasa por señalar los aspectos particulares que permiten la citada prioridad simbólica de la lengua, las propiedades que obligan considerar a esta como el instrumento operativo de un proceso en el que ella misma se halla inserta: el hecho patrimonial. Estos rasgos son los siguientes:

a) La lengua es herencia materna, mientras que el patrimonio es algo que se debe al padre: el reservorio espiritual que se enfrenta así a la herencia material, la que siempre se ha considerado patrimonio inequívoco de todos. Mientras el patrimonio general tiene que ver con el concepto de espacio público, la lengua tiene que ver con el ámbito privado. De hecho, la lengua vehicular es una lengua pidgin, una lengua de paso con la que instrumentalizar la relación turística. La lengua en sentido patrimonial es, como decía Geertz (1987: 89) para la religión, un conjunto de símbolos que suscita motivaciones, formula concepciones y enmarca la realidad: de ahí que mitología y lengua sean dos instrumentos en constante dialéctica.

b) El patrimonio se mide como proceso, como creación propia de los pueblos, una vez superada la barrera del Antiguo Régimen en que todo bien nos era dado y todo mal se debía a nuestra incapacidad de conservarlo. La lengua es necesariamente proceso, incluso lo fue en Babel pese a los esfuerzos por salvar la mutación de los idiomas. La búsqueda de la lengùa perfecta (Eco 1994) fue siempre, motivada por esa particularidad de los hablantes que la dominan imperfectamente pero la usan en conjunto y sin exclusiones, un fracaso.

c) El patrimonio se descubre y se interpreta y la lengua también. Toda profundización léxicosemántica permite pasos adelante para la adquisición de su esencia, porque la lengua, como otros entes patrimoniales, se restaura cuando está viva. Pero la lengua es más bien inconmensurable: hacer un diccionario pragmático de ella, por ejemplo, puede llevar decenas de años.

d) El patrimonio material se muestra con mejor o peor fortuna, pero la lengua es sólo un fondo inmostrable por su dificultad y, sobre todo, para la rapidez que exige el turista.

e) La lengua, como decía Saussure (recogido como apunte en su Curso de Lingüística Gene- 
ra/1916), es un conjunto estructural "où tout se tient"; la fragmentalidad postmoderna no cabe en ella sino a la fuerza.

f) La volatilidad de la lengua es la mayor que se pueda concebir, pero paradójicamente es el recurso más incontrolable del cambio y en su proceso, el más perenne. Las palabras son etéreas, pero muchas de ellas son tan antiguas o más que Tiahuanaco o Macchu Picchu.

g) El patrimonio coadyuva determinadamente a la construcción de la memoria e identidad de los pueblos; la lengua es esa misma memoria colectiva, la que cuando desaparece deja muda a los monumentos y sin identidad a las obras más significativas de un período histórico: sólo se avanzó en la egiptología de modo espectacular, cuando se produjo el desciframiento de la piedra de la Rosetta por Champolion. Como señala Urbano (2000):

\section{el patrimonio creadoporla memoria y la palabra que lo expresa produce en el grupo el sentimien- to de compartir la misma herencia y de atar los lazos que la hacen posible (op. cit. p. 15).}

h) La ecuación que el binomio lengua versus resto del patrimonio crea no es inmutable, sino que constituye un impulso vital para no estancar o reducir la herencia recibida de nuestros mayores, manteniendo su identidad. Pero la lengua, como entidad cambiante no se puede preservar, sino conservar: la lengua no es, antropológicamente hablando, un ente que se hereda, sino una diversidad absolutamente prolija que se aprende colectivamente y de ese modo se conserva.

i) La lengua desprotegida de sus funciones simbólicas de altura, abocada únicamente al uso cotidiano, es una necesidad que ya ejemplifiqué detalladamente arriba: es la fuerza eidética de la palabra corriente. Aprovechada su fuerza simbólica de altura, la que permite decir en algún grado que es concepción del mundo y no sólo proyección del mundo en ella, la lengua nos transplanta al descubrimiento de los principales patrones de conducta por los que se rige un pueblo: la base del porqué de sus símbolos textiles, de la distribución de sus templos, del lugar de su erección o de la fuerza espiritual que emanan. Como ambos estamentos son inseparables, la consideración de un patrimonio sin el pueblo que lo creó y los fundamentos que tuvo para hacerlo, es una caricatura de sí mismo: la obra de un extraterrestre. Es como comprar y vender por Internet en vez hacerlo tratando cara a cara en el proceso de interacción.

j) La lengua de altura mezclada con la lengua de lo cotidiano puede crear patrimonio en si misma: todo acto literario, todo discurso retórico, lo es, siempre que refleje en profundidad el muhu, la semilla ínfima que permite abrir sus frutos. Sólo el discurso desentonado e idiota, el del nacionalismo trasnochado y la utopía barata que implica la exclusión de lo que por necesidad es incluyente, queda vacío en cuanto a patrimonio. Porque, en efecto, la lengua no puede constar únicamente de palabras sublimes aisladas, sino que es un continuo tejido de realidad cotidiana en la que sólo de cuando en cuando se encuentra el patrimonialista con auténticos tesoros.

Recrimino, para terminar, que el DRAE sea ajeno a lo que dice Bákula:

La cultura debe avanzar hermanada al desarrollo pues, asumiendo lo que se ha expresado una y mil veces, es imposible asegurar el progreso de los hombres y sus sociedades, si no tomamos en consideración la dimensión cultural del desarrollo (Bákula 2000: 169).

$Y$ aquí se sitúa, metateóricamente, la lengua. De este modo, con las notas anteriores en que se dibuja la analogía y la diferencia entre la lengua y demás ámbitos del patrimonio, se llega a la paradoja de que las piedras milenarias de Sacsayhuamán o Hatun Rumiyoc no son más perdurables que las palabras quechuas o aimaras que excitan nuestra emoción cuando las conocemos en profundidad. Esto nos mantiene en la idea de que la lengua es un vehículo de expresión que va más allá de lo literario o de lo ideológico, que es el soporte puro de la patrimonialidad in extenso. Reclamo para mi así, con Calderón, el comentario que de inmediato añade a los versos citados arriba:

¡Vive Cristo que parece que vais teniendo razón! (El Alcalde de Zalamea, 877-878) 
$Y$ recalco el principio de prioridad: el experto en patrimonio y turismo debe ser conocedor prioritario de las lenguas vehiculares de su entorno profesional, no como experto en ellas, sino como compromisario del producto, más bien exquisito, que su quehacer vehicula.

Julio Calvo Pérez

Universidad de Valencia, España

julio.calvo@uv.es 


\section{BIBLIOGRAFÍA}

\section{AZURMENDI INTXAUSTI, Mikel}

2000 Nombrar, embrujar: para una historia del sometimiento oral de la cultura en el País Vasco. Zarauz, Alberdania.

\section{BÁKULA, Cecilia}

2000 "Reflexiones en torno al patrimonio cultural", en: Turismo y Patrimonio, 1: 167-174.

CALVO, Julio

1995 a "Análisis crítico de las entradas de origen quechua y aimara en el DRAE $\left(21^{\mathrm{a}}\right.$ ed.)".

Español Actual63: 25-41.

CALVO, Julio

1995 b Universidad y diversidad en los Andes. Anexo 1 de BILCA. Universitat de ValènciaDepartament de Teoria dels Llenguatges.

CALVO, Julio

(en prep.) Nuevo diccionario español-quechua, quechua-español.

\section{CHOAY. Françoise}

1992 L'allégorie du patrimoine. Paris, Éditions du Seuil.

ECO, Humberto

1994 La búsqueda de la lengua perfecta.

Barcelona, Crítica.

FERGUSON, Charles A.

1965 "Dyglossia", en: Word XV: 325-340.

\section{GERZENSTEIN, Ana}

1999 Diccionario etnolingüistico maká-español (DELME), Buenos Aires, Universidad.

GONZÁLEZHOLGUIN, Diego [1607]

1989 Vocabulario de la lengva general de todo el

Perv llamada lengua qqichua o del Inca.

Lima, Francisco del Canto. Ed. facs.

UNMSM.

HOBSBAWM, Eric J. y Terence RANGER (eds.)

1988 L'invent de la tradició. Vic, Eumo.
HUMBOLDT, Wilhem von [1836]

1949 Über die Verschiedenheit des menschlichen Sprachbaues und ihren Einfluss auf die geistige Entwicklung des Menschengeschlechts. Darmstat, Claasen und Toether

LAKOFF, George y Mark JOHNSON

1995 Metáforas de la vida cotidiana. Madrid, Cátedra.

LOHMANN VILLENA, Guillermo

1945 Historia del arte dramático en Lima durante el Virreinato. Madrid, EEHA de la Universidad de Sevilla.

PIAGET, Jean

1950 La construction du réel chez l'enfant. Neuchatel, Delachux et Niestlé. Edición española: La construcción de lo real en el niño. Buenos Aires, Nueva Visión, 1976.

PERROUD, Pedro Clemente y Juan $\mathrm{M}^{\mathrm{a}} \mathrm{CHOUVENC}$ 1970 Diccionario castellano kechwa, kechwa castellano. Santa Clara, Seminario San Alfonso, Padres Redentoristas.

PORRAS BARRENECHEA, Raúl

1999 Indagaciones peruanas: el legado quechua. Tomo I de sus obras completas, prologado por Félix Álvarez Brun. Lima, UNMSM-IRPB

PRATS, Llorenç

1997 Antropología y patrimonio. Barcelona, Artiel

TENIER, Marie

2000 En torno al debate sobre la noción de patrimonio", en: Turismo y Patrimonio, 1:179- 181.

URBANO, Henrique

2000 "Patrimonio y modernidad", en Turismo y Patrimonio, 1: 13-25.

VYGOTSKY, Lev Semenovich

1972 Pensamiento y lenguaje. Buenos Aires, 